\title{
Design and Fabrication of a Hand Operated Small Scale Maize Sheller
}

\author{
Sharmistha Sahu ${ }^{1 *}$, Geetanjali Dhupal ${ }^{1}$ and Jogendra Soren ${ }^{2}$ \\ ${ }^{1}$ Department of Agricultural Engineering with Specialization in Farm \\ Machinery and Power at Centurion University of Technology and Management, \\ Paralakhemundi, Odisha-761211, India \\ ${ }^{2}$ Department of Agricultural Engineering, (Dec 2018- Jan 2020), at Centurion University of \\ Technology and Management, Paralakhemundi, Odisha-761211, India \\ *Corresponding author
}

\section{A B S T R A C T}

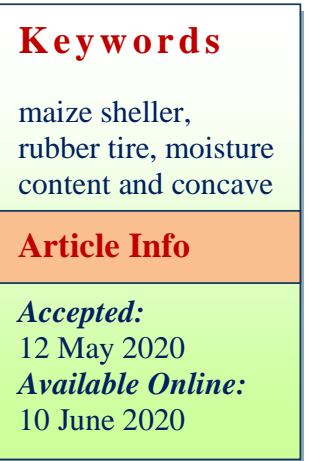

After paddy and wheat maize is the third most important crop in India. Maize is known as king of fodder and queen of cereals due to its great importance in human and animal diet. The traditional shelling of maize is by using hands by rubbing the maize cobs, or after complete drying rubbing the maize cobs open each other or on any hard frictional surface. These methods are tedious and time consuming also involves drudgery like muscular pain. Here the study was undertaken for the small and marginal farmers to survey the different shelling methods used by them for maize. In this project we have solved the problem by providing low cost and hand operated maize sheller having good efficiency as well as cost economy for small and marginal farmers. Here the small scale maize sheller consist of a rubber tire mounted on a frame and a shaft attached to it below which a concave is provided, feeding of sundried maize with moisture content 10-20 per cent is done at the clearance between the tire and the concave so that rubbing action occurs between the tire and the concave and shelling of maize will be there. The clearance between concave and tire is adjustable so any size of maize can be shelled. Here the shelling productivity of hand operated maize sheller was found to be higher as compared to manual shelling and shelling efficiency decreased with increasing the moisture content and increased by increasing rotational speed.

\section{Introduction}

Maize is one of the most important cereal crops of the world and contributes to food security in most of the developing countries. In India, maize is emerging as third most important crop after rice and wheat. Its importance lies in the fact that it is not only used for human food and animal feed but at the same time it is also widely used for corn starch industry, corn oil production, baby corns etc. (Dr. A. Didar Singh, Secretary General, FICCI) The global maize revolution is characterized by new technology, consumer demand and industrial farming.

Maize has become is today used as an important raw material in food processing, poultry, dairy, meat and ethanol industry and along with its traditional uses makes it one of the fastest growing cash crops in the world. Indian is an agriculture oriented country; 
where around $60 \%$ of population is depend on agriculture. Agriculture plays a vital role in the improvement of Indian economy as it contributes about $17 \%$ to the total GDP and provides employment to over $60 \%$ of the population. Indian agricultural statistics 2018 indicates that the production of maize from all over India is 28.72 million tones from 9.5 million hector land.

Small and marginal farmers with less than two hectares of land account for $86.2 \%$ of all farmers in India, but own just $47.3 \%$ of the crop area, according to provisional numbers from the 10th agriculture census 2015-16. Marginal Farmer' means a farmer cultivating (as owner or tenant or share cropper) agricultural land up to 1 hectare (2.5 acres). 'Small Farmer' means a farmer cultivating (as owner or tenant or share cropper) agricultural land of more than 1 hectare and up to 2 hectares (5 acres).

Maize shelling is always a tedious and difficult job, so to make farmers less drudgery and put less effort, we need to develop the farm mechanization in maize shelling machine keeping in mind to the cost economy. Tanko Bakoland Boman James Bature (2017) design, fabricate and performance evaluation of a hand operated maize sheller. The average kernel shelling capacity and shelling efficiency of the sheller was $22.06 \mathrm{~kg} / \mathrm{hr}$ and $75.03 \%$ is better than the conventional finger palm shelling method which has been reported to have $12.63 \mathrm{~kg} / \mathrm{hr}$ average kernel shelling capacity and $100 \%$ shelling efficiency. The average level of visible grain damage to the detached kernels recorded was $1.3 \%$. Thus the sheller seems to solve the problem that rural and small scale farmers regarding maize shelling. The total cost of the machine will be N 26,797.50 based on current market price. Girish Karikatti (2015) developed a crank operated maize sheller using ergonomic and mechanical considerations for dehusking and shelling Dehusking is a tedious and separate activity that precedes shelling that brings additional burden on farmers. It consists of feeder from where the maize is inserted. The crank is connected to the blade. When the crank is turned, the blade rotates and shells the maize. The machine is operated by 1 person and requires feeding of cobs one by one.

David O Aremu (2014) done the design, fabricate and performance evaluation of a motorized Maize shelling machine. The performance evaluation was carried out using the NIS standard. Result showed that shelling efficiency, cleaning efficiency, grain recovery efficiency and output capacity were $87.08 \%$, $95.89 \%$ and $623.99 \mathrm{~kg} / \mathrm{hr}$ respectively which were at highest values at $13 \%$ moisture contents of maize and at 886rpm shelling speed which results in high efficiency.

Keeping these reviews in mind our aim is to design a low cost handy maize sheller for small and marginal farmers to reduce the labour and drudgery. So the project consists of these following objectives include Design and fabrication of hand operated small scale maize Sheller. And also study about Performance evaluation of hand operated small scale maize Sheller.

\section{Materials and Methods}

This chapter describes about the design and fabrication of hand operated maize sheller and its performance evaluation comparison with manual maize shelling. The experiments were conducted at Centurion University of Technology and Management, Paralakhemundi, Odisha and farmer survey was done in Paralakhemundi block.

The methods of designing the maize sheller is done in three phases, the collection of rural farmer Sheller needs associated with 
agricultural operation, the design of an appropriate shelling system to meet their needs and to determine whether their problem will be solved.

\section{Construction features}

\section{Frame}

The frame was made up of mild steel. The overall dimensions of frame were $30 \mathrm{~cm}$ length, $60 \mathrm{~cm}$ width and $105 \mathrm{~cm}$ height. The sheller unit was fixed to this framework.

\section{Rotating wheel}

The diameter of rotating wheel is $57 \mathrm{~cm}$ and width is $18 \mathrm{~cm}$. we have selected a worn out wheel for this purpose.

\section{Hopper}

The hopper was fabricated in trapezoidal shape and dimensions of $25 \mathrm{~cm}$ length, $15 \mathrm{~cm}$ width and $25 \mathrm{~cm}$ height. It is placed on the outer casing for feeding the maize cobs

\section{Concave}

Concave with $66 \mathrm{~cm}$ length and $2 \mathrm{~cm}$ diameter opening and the clearance between concave and rotating wheel is $3-6 \mathrm{~cm}$.

\section{Outer cover}

$120 \mathrm{~cm}$ diameter with 3mm Mild Steel sheets.

\section{Working of hand operated maize sheller}

The maize sheller is made of a used rubber tire mounted in a metal housing with a concave wire screen bottom. As the wheel is cranked maize enter the space between the tire and concave screen. In operation the maize is fed into the clearance between the worn out rubber tire and concave while the rubber tire is turning. The maize is then shelled by rubbing action between the rubber tire and the ms rods with diameter of $10 \mathrm{~mm}$. After the maize has been shelled the grains fall through the ms rods and the cob.

As we have made a low cost maize sheller for small and marginal farmers so we have done some basic experiments by going to the level of a poor farmer, we have dried the maize in sun like most of the poor farmers do in our country and then we have tested our maize sheller by feeding sundried maize through the hopper.

The rotating tire produced two kinds of forces namely impact and shearing which caused to remove grains from maize cobs and kernels were collected at the bottom end of the outlet. Two persons were engaged for these operations, one for feeding maize cobs at hopper and the other for rotating the pulley.

The shelled grains were collected at the bottom of the outlet. Weight of whole grains, broken grains and unshelled cobs from all outlets were recorded and time of operation to calculate feeding capacity, shelling efficiency and visible damage percentage, were also recorded.

The developed sheller was tested as per the standard procedures (Indian Standard test code for power maize sheller IS: 7052.1973) for combination of various moisture contents i.e., 10, 12, 14, 16, 18 and $20 \%$ w.b. and different feed rates i.e., 30,40 and $45 \mathrm{~kg} / \mathrm{h}$. These three feed rates corresponded to 90 , 100 and $120 \mathrm{rpm}$ of the cylinder, respectively.

Weight of whole grains, broken grains and unshelled cobs from all outlets we rerecorded and time of operation to calculate feeding capacity, shelling efficiency and visible damage percentage, were also recorded. 


\section{Performance evaluation of hand operated maize sheller}

The performance evaluation of the machine was carried out at six levels of moisture content $(10,12,14,16,18,20 \%$ w.b.), to observe the performance evaluation of machine at lower moisture content i.e. $10 \%$ w.b. taken, than the optimum moisture content i.e. $12 \%$ w.b.

The hand operated maize sheller was tested with local maize variety at six levels moisture contents ranging from 10 to $20 \%$ w.b. and feed rates of $40 \mathrm{~kg} / \mathrm{h}$ at 90,100 and $120 \mathrm{rpm}$, respectively.

The weight of whole grains, broken grains and unshelled cobs from all outlets were recorded at the time of operation and feeding capacity, sheller productivity, shelling efficiency and broken percentage were determined by following formulas:

\section{Sheller productivity}

At each treatment, shelled grains weight and the shelling time (T) in seconds were recorded, then the machine productivity $(\mathrm{Mp})$, ton/h was calculated as follows:

$\mathrm{Mp}=\frac{M t \times 3600}{t \times 1000}$

Where:

$\mathrm{Mt}=$ Mass of total grains in the sample, $\mathrm{kg}$. $\mathrm{t}=$ Shelling time, $\mathrm{sec}$

\section{Efficiencies of sheller}

Percentage by weight of shelled grains from all outlets of the sheller with respect to total grain input and it is calculated by the following formulae. (IS: 7052.1973)

Shelling efficiency $(\%)=100-$ percentage of unshelled grains

\section{Determination of total losses}

\section{Grain content}

Ten samples (each sample not less than $1 \mathrm{~kg}$ ) of the cobs were taken at random.

The grain was separated manually and the ratio of weight of grain and shelled cob was taken as grain content. The average of the ten samples shall be taken as grain and shelled cob ratio (IS: 7052-1973).

\section{Total grain input}

Total grain input $=$ Feed rate $\mathrm{x}$ Grain content, $\mathrm{kg}$

\section{Unshelled cobs}

Unshelled grain from all outlets with respect to total grain input, expressed as Percentage by weight (IS: 7052.1973).

Unshelled grain (\%)

$$
=\frac{100 \times u n s h e l l e d \text { grain obtained from all outlets in } \mathrm{kg}}{\text { total grain input }}
$$

\section{Visible damage}

Visible damage grains from the specified grain outlet with respect to total grain received at outlet expressed as percentage by weight (IS:7052.1973).

Visible Damage (\%)

$$
=\frac{100 x b r o k e n \text { grain obtained from all outlets in } \mathrm{kg}}{\text { total grain input }}
$$

\section{Results and Discussion}

The maize sheller was tested at 6 level of moisture content ranging from 10 to 20 per cent w.b at a feed rate of $40 \mathrm{~kg}$ per hour for calculating the sheller productivity and it was 
compared with the traditional method of maize shelling. The hand operated maize sheller was tested with local corn at six levels moisture contents ranging from 10 to $20 \%$ w.b. and feed rates of $40 \mathrm{~kg} / \mathrm{h}$ at 90,100 and $120 \mathrm{rpm}$, respectively. The weight of whole grains, broken grains and unshelled cobs from all outlets were recorded. The results are analysed for shelling efficiency, unshelled grain (\%) and visible grain damage (\%) with respect to different moisture content.

\section{Shelling productivity}

The shelling productivity of hand operated maize sheller was found to be higher as compared to manual shelling all moisture contents at feed rate of $40 \mathrm{~kg} / \mathrm{h}$. The shelling productivity $(0.79$ ton $/ \mathrm{h})$ is higher as compared to manual operation $(0.23 \mathrm{ton} / \mathrm{h})$ at moisture content of $10 \%$ w.b. Similarly the shelling efficiency percentages for hand operated maize sheller and manual method are 0.68 and $0.19,0.64$ and $0.14,0.53$ and $0.11,0.49$ and $0.09 \& 0.42$ and 0.075 ton/h, at moisture contents of $12,14,16,18$ and $20 \%$ w.b. respectively (fig. 2). Here from (fig.3) we observed that the shelling productivity decreases with increase in moisture content.

\section{Shelling efficiency}

Table 2. Shows the effect of rotational speed and grains moisture content on shelling efficiency. It could be seen that the shelling efficiency decreased with increasing the moisture content and increased by increasing rotational speed, where it increased from 97.34to $99.43 \%$ at $10 \%$ moisture content, from 96.08 to 99.01 at $16 \%$ moisture content and it increased from 94.25 to 98.88 at $20 \%$ corn grains moisture content when the rotational speed increased from 90-120 rpm.

Table.1 Details of the construction feature of manual maize sheller machine

\begin{tabular}{|c|c|}
\hline Particulates & Dimension \\
\hline Frame & $105 \times 60 \times 30 \mathrm{~cm}$ \\
\hline Hopper & $25 \times 15 \times 25 \mathrm{~cm}$ \\
\hline Outer cover & $120 \mathrm{~cm}$ diameter \\
\hline Rotating wheel & $57 \mathrm{~cm}$ diameter, $18 \mathrm{~cm}$ width \\
\hline Wheel Concave Clearance & $3-6 \mathrm{~cm}$ \\
\hline Concave & $\begin{array}{l}\text { Concave with } 66 \mathrm{~cm} \text { length and } 2 \mathrm{~cm} \text { diameter } \\
\text { opening }\end{array}$ \\
\hline
\end{tabular}

Table.2 Effect of rotational speed (rpm) and grains moisture content on shelling efficiency

\begin{tabular}{|c|c|c|c|}
\hline \multirow{2}{*}{\begin{tabular}{c} 
Moisture content \\
\multirow{2}{*}{$(\boldsymbol{\%})$}
\end{tabular}} & \multicolumn{3}{|c|}{ Rotational speed(rpm) } \\
\cline { 2 - 4 } & 90 & 100 & $\mathbf{1 2 0}$ \\
\hline \multirow{10}{10}{} & 97.34 & 98.77 & $\mathbf{9 9 . 4 3}$ \\
\hline $\mathbf{1 2}$ & 97.01 & 98.10 & $\mathbf{9 9 . 3 3}$ \\
\hline $\mathbf{1 4}$ & 96.11 & 97.95 & $\mathbf{9 9 . 2 6}$ \\
\hline $\mathbf{1 6}$ & 96.08 & 97.38 & $\mathbf{9 9 . 0 1}$ \\
\hline $\mathbf{1 8}$ & 95.90 & 97.12 & $\mathbf{9 8 . 9 4}$ \\
\hline $\mathbf{2 0}$ & $\mathbf{9 4 . 2 5}$ & $\mathbf{9 6 . 9 5}$ & $\mathbf{9 8 . 8 8}$ \\
\hline
\end{tabular}



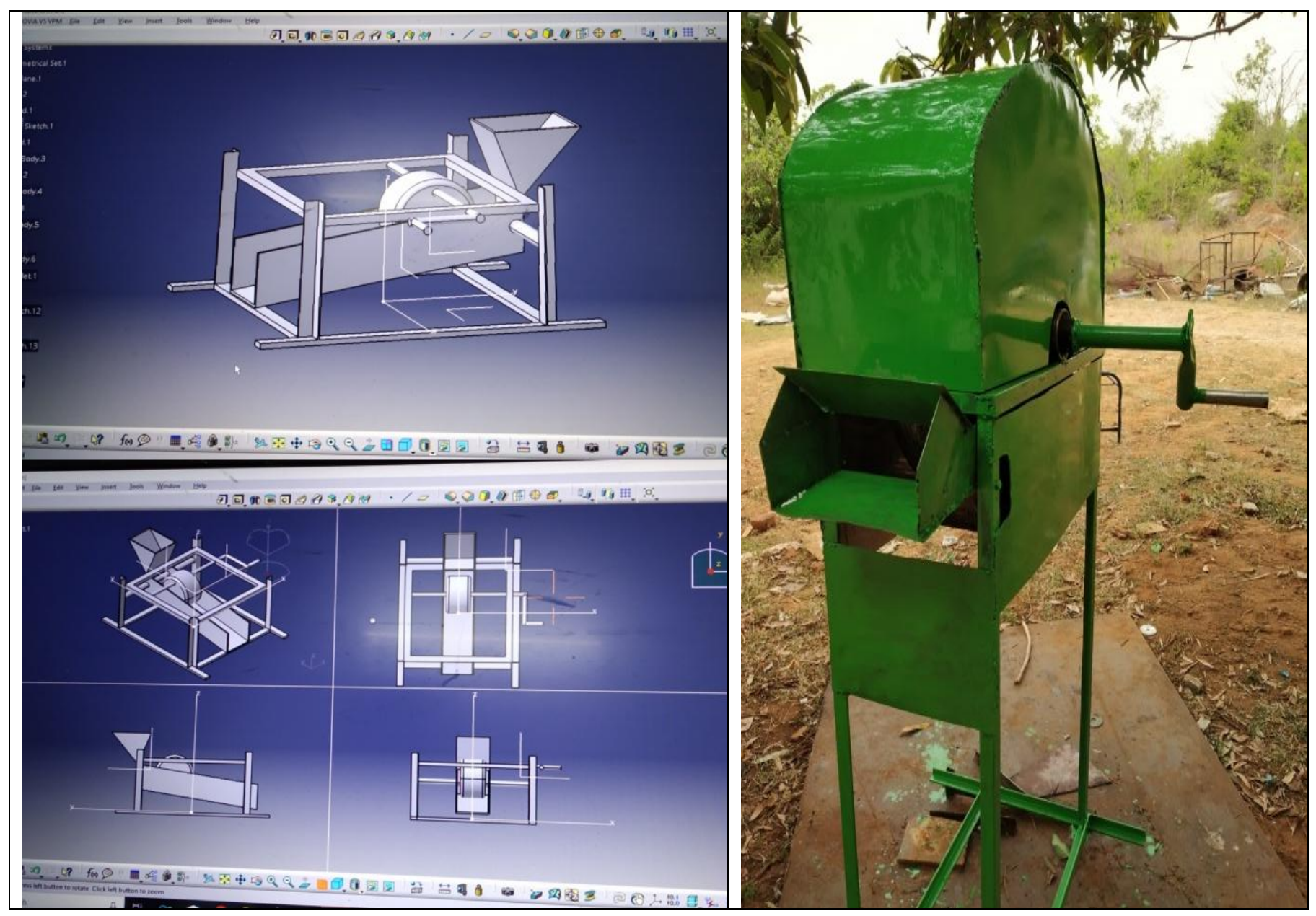

Fig.1 Hand operated maize sheller with its CATIA design

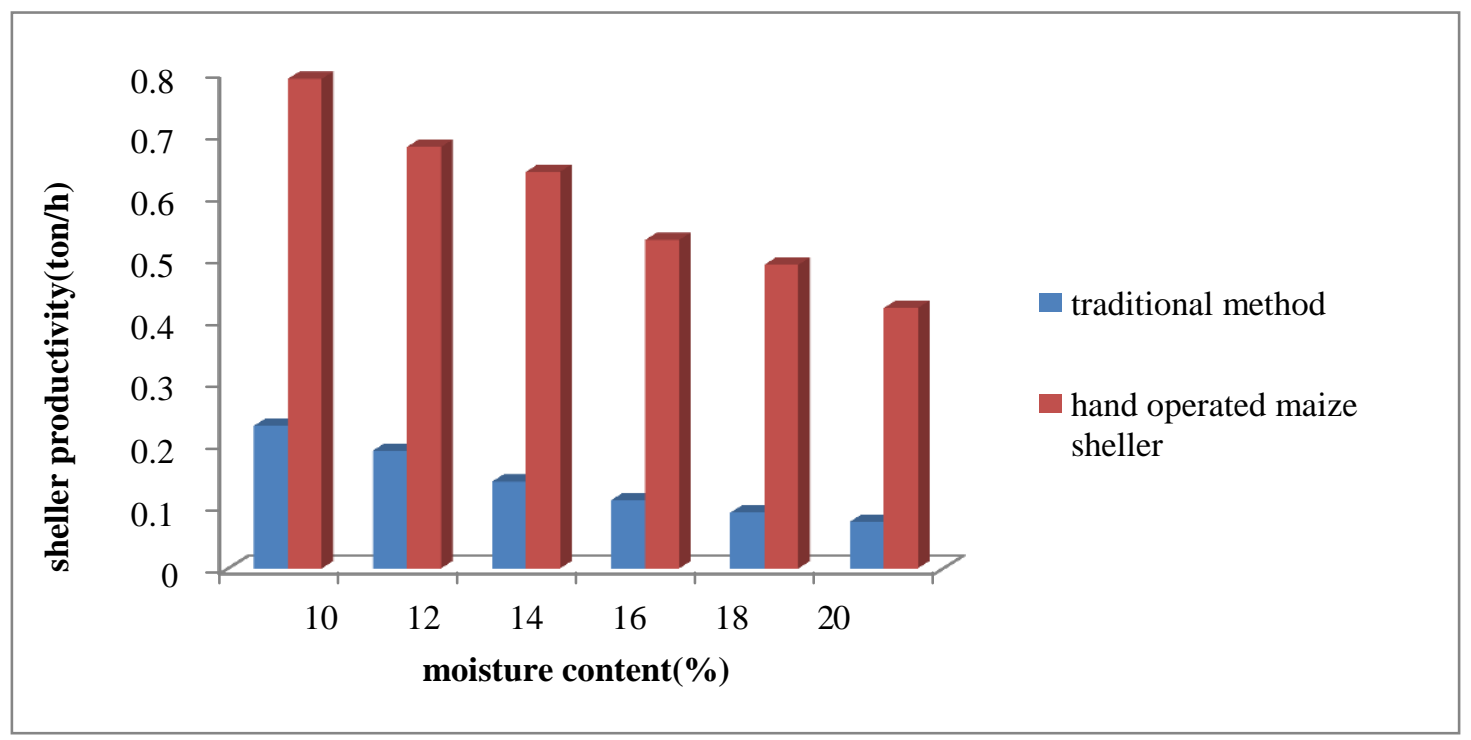

Fig.2 Shelling productivity at different $\mathrm{mc}$ and its comparisons with traditional shelling 


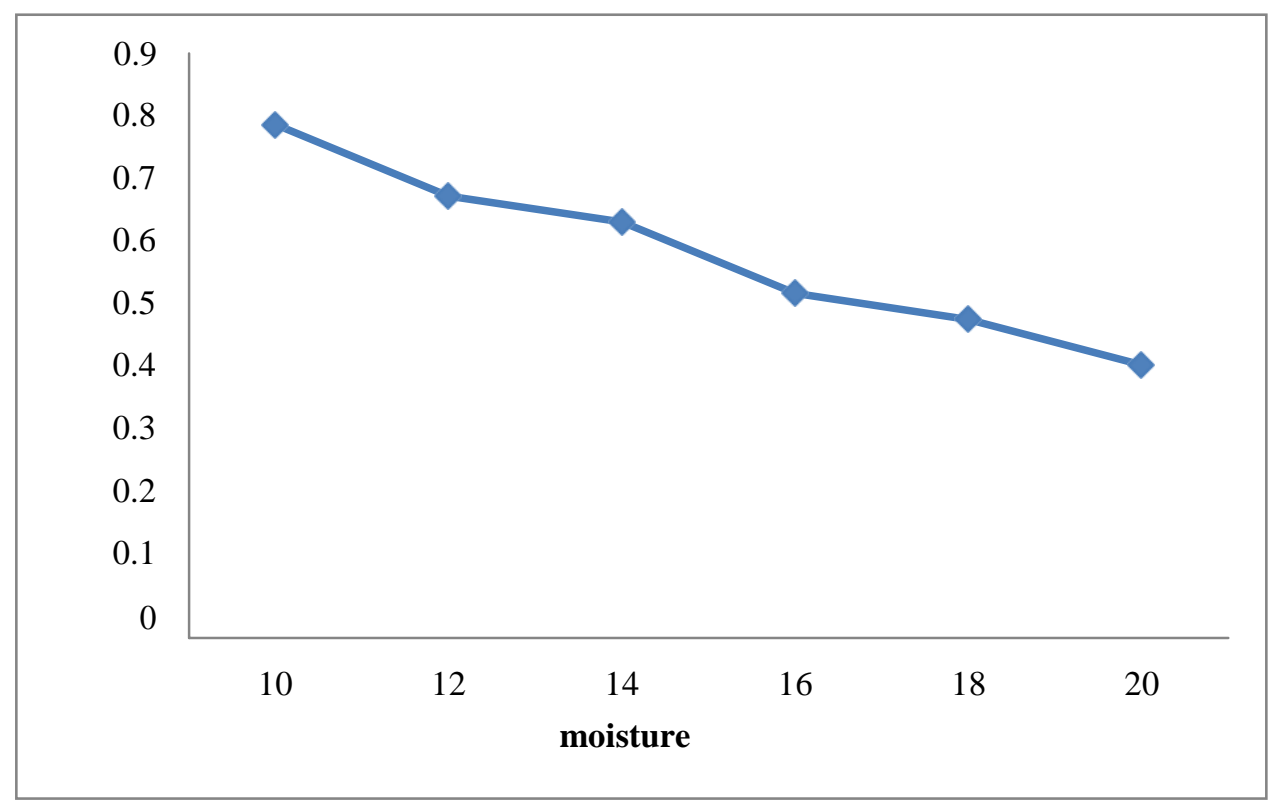

Fig.3 Sheller productivity of hand operated maize sheller at different moisture content

A local corn sheller was evaluated at rotational speeds of $(90,100$ and $120 \mathrm{rpm})$ and moisture contents of $(10,12,14,16,18$ and $20 \%$ ) of corn grains.

The sheller productivity, shelling efficiency, unshelled grains and grain damage were determined. The most important results obtained are summarized as follows:

By using the local corn sheller, sheller productivity, shelling efficiency and the ranged from 0.075 to 0.79 ton $/ \mathrm{h}$, from 94.25 to $99.43 \%$ respectively.

The percentage of grain damage and percentage of unshelled grains ranged from 0.49 to $3.23 \%$, and 0.31 to $2.13 \%$ respectively.

Shelling productivity of hand operated maize sheller decreases with the increase in moisture content, at 10 per cent moisture content the productivity is 0.79 ton $/ \mathrm{h}$ whereas at 20 per cent moisture content the shelling productivity found to be 0.42 ton $/ \mathrm{h}$.

It could be concluded that the shelling efficiency decreased with increasing the moisture content and increased by increasing rotational speed, where it increased from 97.34 to $99.43 \%$ at $10 \%$ moisture content, from 96.08 to 99.01 at $16 \%$ moisture content and it increased from 94.25 to 98.88 at $20 \%$ corn grains moisture content when the rotational speed increased from 90-120 rpm.

The unshelled grains increased with increasing the moisture content and decreased by increasing rotational speed, where it decreased from 1.03 to $0.49 \%$ at $10 \%$ moisture content, from 1.44 to $0.62 \%$ at $14 \%$ moisture content and it decreased from 3.23 to $1.86 \%$ at $20 \%$ corn grains moisture content when the rotational speed increased from 90- $120 \mathrm{rpm}$.

It could be seen that the Grain damage increased with increasing the moisture content and increased by increasing rotational speed, where it increased from 0.38 to $0.97 \%$ at $12 \%$ moisture content, from 1.27 to $1.53 \%$ at $16 \%$ moisture content and it increased from 1.47 to $2.13 \%$ at $20 \%$ corn grains moisture content when the rotational speed increased from 90-120 rpm. 


\section{References}

Bako, T. and Boman, J.B., 2017. Design, fabrication and performance evaluation of a hand operated maize sheller. Journal of American Science, 13(8), pp.68-76.

Karikatti, G., Jangali Satish, J., Kathani, A., Lokeshwar, R. and Sattur, S., 2015. Crank Operated Maize Sheller. International Journal for Scientific Research \& Development, 3, pp.561-564.

Mali, P.K., Sakhale, D.C. and Shelare, S.D., 2015. A Literature Review On Design And Devlopement Of Maize Thresher. Volume, 3(9), pp.9-14.
Ogunlade, C.A., Aremu, D.O., Babajide, N.A. and Akinyele, A.O., 2014. Design, fabrication and performance evaluation of a power (motorised) maize shelling machine. In Proceedings of the Third International Conference on Engineering and Technology Research August (pp. 5-7).

Sahu, S., Development of a decision support system for optimum selection of power source for paddy groundnut cropping system (Doctoral dissertation, CAET, OUAT).

Sahu, S., Parida, C. and Mishra, J.N., 2019. Study on health hazards of workers in coir industry'.

\section{How to cite this article:}

Sharmistha Sahu, Geetanjali Dhupal and Jogendra Soren. 2020. Design and Fabrication of a Hand Operated Small Scale Maize Sheller. Int.J.Curr.Microbiol.App.Sci. 9(06): 31-38.

doi: https://doi.org/10.20546/ijcmas.2020.906.004 